\title{
Regression of colon cancer and induction of antitumor immunity by intratumoral injection of adenovirus expressing interleukin-12
}

\author{
Guillermo Mazzolini, Cheng Qian, Xiaoming Xie, Yonglian Sun, Juan J. Lasarte, \\ Marek Drozdzik, and Jesús Prieto.
}

\author{
Division of Hepatology and Gene Therapy, Department of Medicine, School of Medicine and Clinica \\ Universitaria, University of Navarra, Pamplona, Spain.
}

\begin{abstract}
Interleukin-12 (IL-12) has been shown to possess potent immunoregulatory and antitumoral effects. We have evaluated the anti-oncogenic potential and the mechanisms of the antitumoral effect of in vivo adenovirus-mediated transfer of IL-12 gene in a murine model of colon cancer. AdCMVIL-12 was constructed to permit coordinated production of p40 and p35 subunits of IL-12 gene to obtain the maximum IL-12 bioactivity. Infection of murine colon cancer CT-26 cells in vitro with AdCMVIL-12 resulted in the production of high levels of IL-12. In vivo gene therapy of colon cancer nodules by intratumoral injection of AdCMVIL-12 induced a local increase in IL-12 and interferon- $\gamma$ levels and a complete regression of the tumor in 26 of 34 (76\%) mice. Tumor disappeared between days 7 and 10 after vector administration. The antitumoral effect was mediated by CD8 ${ }^{+} \mathrm{T}$ cells and was associated with the generation of cytotoxic T lymphocytes against colon cancer cells. Animals that eliminated the tumor were protected against a second administration of neoplastic cells. Treatment with AdCMVIL-12 of one tumor nodule also caused regression of established tumors at distant sites. These data demonstrate that AdCMVIL-12 is a useful therapeutic tool for established colon cancer in mice and should be considered for application in humans.
\end{abstract}

Key words: Gene therapy; adenovirus; interleukin-12; colon cancer; animal model; cytotoxicity.

$\mathrm{C}$ olorectal carcinoma is highly prevalent in most Westernized countries, with an incidence that appears to rise steadily from the second to ninth decade of life. Progression of the disease occurs through invasion of the colonic wall, involvement of regional lymph nodes, and distant metastasis. At the time of diagnosis, approximately half of patients have tumors invading through the bowel wall with spread to regional lymph nodes; in addition, $10 \%$ of patients present with synchronous metastatic cancer to the liver, which may be the presenting manifestation of the disease. ${ }^{1}$

Surgery is associated with a $90 \% 5$-year survival rate in patients with tumors involving only the mucosa or submucosa. However, in those patients with transmural penetration, survival decreases to $60-80 \%{ }^{2}$ only $\sim 30-$ $60 \%$ of patients with regional lymph node metastasis ${ }^{3}$ and $<6 \%$ of those with distant metastasis are disease free at 5 years. $^{4}$ At present there is no therapeutic regime capable of prolonging survival in patients with

Received August 24, 1998; accepted November 8, 1998.

Address correspondence and reprint requests to Dr. Cheng Qian or Prof. Jesús Prieto, Division of Hepatology and Gene Therapy, Department of Medicine, Medical School, University of Navarra, 31080 Pamplona, Spain.E-mail address: cqian@unav.es or jprieto@unav.es

(c) 1999 Stockton Press 0929-1903/99/\$12.00/+0 advanced colon cancer. Thus, this disease remains a formidable therapeutic challenge.

The use of gene therapy to enhance immunological responses against tumor cells has emerged as a promising new approach to treat cancer. ${ }^{5-8}$ Systemic treatment with cytokines or, even better, the induction of local production of cytokines in the proper tumor mass, can attract and activate different types of immunocytes and create an inflammatory response leading to tumor rejection. ${ }^{5-9}$ Among the different cytokines, interleukin-12 (IL-12) is of particular interest because of its critical role in the stimulation of cell-mediated immunity. ${ }^{10}$ IL-12, which is mainly produced by antigen-presenting cells, has been shown to augment the cytotoxic activity of natural killer and activated $\mathrm{T}$ cells, to induce the production of interferon- $\gamma$ (IFN- $\gamma$ ), and to promote the differentiation of uncommitted $\mathrm{T}$ lymphocytes to $\mathrm{T}$ helper type 1 cells. ${ }^{10-15}$

Because of its potent biological activities, IL-12 is considered to be a promising substance in cancer immunotherapy. ${ }^{11,16}$ However, although systemic administration of IL-12 has been shown to be highly effective in inducing tumor regression and reducing metastases in diverse murine models of solid tumors, ${ }^{9,17-21}$ important hematological, hepatotoxic, and muscular side effects seriously limit its use as an anticancer agent. ${ }^{13,21,22}$ Thus, although a phase I clinical trial of systemic IL-12 treat- 
ment in subjects with renal cell carcinoma showed objective tumor responses in several patients, a subsequent phase II trial of IL-12 in advanced renal cell cancer was discontinued because of severe toxicity, including death. ${ }^{23,24}$

It seems therefore that the use of procedures allowing high local production of IL-12 at the site of interest (the tumor mass) without increasing systemic levels of the cytokine would probably achieve therapeutic effects without toxicity. To this aim, different strategies based on the transduction of tumoral cells with IL-12 genes have been attempted to treat various neoplasms. ${ }^{25-36}$

One of systems enabling efficient in vivo transduction of tumoral cells is the use of adenoviral vectors. These vectors can be produced at high titers, can transduce a wide variety of cell types independently of cell cycle, and can induce high levels of transgene expression. ${ }^{37}$ In the present paper, we have used a murine model of syngenic colon cancer to evaluate the anti-oncogenic potential of in vivo transduction of established tumors with an adenoviral vector (AdCMVIL-12) expressing high levels of bioactive IL-12. Our results showed that intratumoral (i.t.) administration of the vector caused regression of the treated nodule and of distant lesions and induced long-lasting protective immunity against tumor rechallenge without any apparent toxic effect. The antitumoral effect of the treatment was shown to be largely mediated by $\mathrm{CD}^{+} \mathrm{T}$ cells and was associated with the emergence of a potent cytotoxic T-cell response against tumoral cells. These results provide an experimental basis for consideration of this therapy as a possible treatment for colon cancer in humans.

\section{MATERIALS AND METHODS}

\section{Construction of adenovirus}

Recombinant adenovirus carrying IL-12 under the control of the cytomegalovirus (CMV) promoter was constructed as follows: A HindIII/SpeI fragment of pBS/p35 with cDNA of the p35 subunit of IL-12 was filled in by Klenow and blunt-end ligated into BamHI-cut pMV100, which carries the CMV promoter and a poly(A) signal. The resultant plasmid was cut by HindIII to release a p35 expression cassette that was ligated into EcoRI-cut pDE1sp1A by blunt-end ligation (pDE1sp1A/ $\mathrm{p} 40)$. A $N$ coI/SmaI fragment of $\mathrm{pBS} / \mathrm{p} 40$ containing the $\mathrm{p} 40$ subunit of IL-12 was cloned into NcoI/EcoRV-cut pCITE-1 carrying internal ribosome entry site (IRES). The resultant plasmid was cut by EcoRI to release the IRES/p40 fragment; this fragment, in turn, was cloned into EcoRI-cut p $\Delta \mathrm{E} 1 \mathrm{sp} 1 \mathrm{~A} /$ $\mathrm{p} 40$ to form $\mathrm{p} \Delta \mathrm{E} 1 \mathrm{sp} 1 \mathrm{~A} / \mathrm{IL}-12$. A BamHI/SalI fragment containing CMV promoter, p35, IRES p40, and poly(A) signal was cloned into HindIII-cut adenovirus plasmid pMV60 to form pMV60/IL-12. pMV60/IL-12 and pJM17 were cotransfected into 293 cells, and plaques were screened to obtain AdCMVIL12. Adenovirus carrying lac $Z$ reporter gene under the control of the CMV promoter (AdCMVlacZ) was produced as described previously. ${ }^{38}$ Recombinant adenoviruses were isolated from a single plaque, expanded in 293 cells, and purified by double $\mathrm{CsCl}$ ultracentrifugation. The purified virus was extensively dialyzed against $10 \mathrm{mM}$ tris(hydroxymethyl)aminomethane $/ 1 \mathrm{mM} \mathrm{MgCl}_{2}$ and stored in aliquots at $-80^{\circ} \mathrm{C}$. The virus titer was determined by plaque assay.

\section{Animals, cell culture, and reagents}

We used 5- to 8-week-old BALB/c female mice in this study. They were purchased from Charles River (Barcelona, Spain). During the experimental period, animals were housed under standard conditions according to institutional guidelines.

We obtained 293 cells (adenoviral E1-transformed human embryonic kidney cells) from the American Type Culture Collection (Manassas, Va). The CT-26 tumor cell line, an undifferentiated murine colorectal adenocarcinoma cell line, ${ }^{39}$ was established from an $N$-nitroso- $N$-methylurethan-induced transplantable tumor ${ }^{40}$ in $\mathrm{BALB} / \mathrm{c}\left(\mathrm{H}-2^{\mathrm{d}}\right)$ mice; this cell line was a kind gift of Dr. K. Brand, Max-Planck-Institut fur Biochemie (Berlin, Germany). 293 cells were maintained in Dulbecco's modified Eagle's medium supplemented with $10 \%$ heat-inactivated fetal calf sera (FCS), 2 mM L-glutamine, 100 $\mathrm{U} / \mathrm{mL}$ streptomycin, and $100 \mu \mathrm{g} / \mathrm{mL}$ penicillin. CT-26 cells were maintained in RPMI 1640 medium supplemented with $10 \%$ heat-inactivated FCS, $2 \mathrm{mM}$ L-glutamine, $100 \mathrm{mg} / \mathrm{mL}$ streptomycin, 100 and $\mathrm{U} / \mathrm{mL}$ penicillin.

All cell culture reagents were obtained from Biological Industries (Beit Haemek, Israel); tissue culture dishes and enzyme-linked immunosorbent assay (ELISA) plates were obtained from Greiner Labortecknik (Nürtingen, Germany) and Nunc (Roskilde, Denmark).

\section{In vivo gene therapy of established tumors using AdCMVIL-12}

Colon carcinoma was established by subcutaneous (s.c.) implantation of CT-26 cells. An aliquot of $5 \times 10^{5}$ cells was injected into the right hind flank of syngenic mice. After $\sim 10$ days, when the tumor reached $5 \mathrm{~mm}$ in diameter, different doses of recombinant adenoviruses (AdCMVIL-12 at $10^{8}$ plaque-forming units (PFU) and $10^{9}$ PFU; AdCMVlacZ at $10^{9}$ PFU) were injected i.t. in a volume of $50 \mu \mathrm{L}$ diluted in saline. Tumor growth was monitored two times per week by measuring two perpendicular tumor diameters using calipers. Tumor volume was calculated from the square of the longest diameter (b) multiplied by a smaller diameter (a) of tumor according to the following formula: $\mathrm{V}=\mathrm{a} \times \mathrm{b}^{2}$. Animals with tumors that were $>1.5 \mathrm{~cm}$ in two perpendicular diameters or $>2.0 \mathrm{~cm}$ in one diameter were sacrificed for ethical reasons.

To treat bilateral tumors, $5 \times 10^{5} \mathrm{CT}-26$ cells were injected s.c. into BALB/c mice in the right and left hind lank. When the tumor on both sides reached $5 \mathrm{~mm}$ in diameter, the right tumor was treated by an i.t. injection of $10^{8}$ of AdCMVIL-12 $(n=7)$ or with the same dose of control vector AdCMVlacZ $(n=4)$. After treatment, the size of the tumors was measured as described above.

To study protective immunity against rechallenge with tumoral cells, animals that were free of disease at 2 weeks, 2 months, and 4 months after complete regression of primary tumors were rechallenged with $5 \times 10^{5} \mathrm{CT}-26$ cells at a distal site. Age-matched naive animals received the same amount of cells to serve as controls.

\section{Cytokine production}

To evaluate the production of IL-12 by CT-26 cells in vitro, we infected $10^{6}$ cells with AdCMVIL-12 or AdCMVlacZ at MOIs (multiplicities of infection) of 1000, 100, 10, and 1. After 2 days, supernatants from infected cells were collected for the determination of IL-12 concentration by ELISA. To estimate the in vivo production of cytokines after treatment of the tumors with adenoviruses, tumor tissue, blood samples, and 
spleen were collected at 1, 3, and 5 days posttreatment. Blood was collected from the retro-orbital sinus. Tumor and spleen were removed and frozen in liquid nitrogen. Frozen tissue was homogenized in $0.5 \mathrm{~mL}$ of phosphate-buffered saline (PBS) containing $100 \mu \mathrm{M}$ phenylmethylsulfonyl fluoride and 10 $\mu \mathrm{g} / \mathrm{mL}$ aprotinin (ICN Iberica, Barcelona, Spain). The homogenate was then sonicated for 10 seconds and cleared by centrifugation in a microcentrifuge for 5 minutes at room temperature. Samples were stored at $-20^{\circ} \mathrm{C}$.

ELISAs for IL-12 and IFN- $\gamma$ were performed as described by Chensue et al. ${ }^{41}$ The 96 -well microtiter plates were coated overnight with anti-cytokine capture monoclonal antibody (Ab) (PharMingen, San Diego, Calif) (4 $\mu \mathrm{g} / \mathrm{mL}$ anti-IL-12 and $4 \mu \mathrm{g} / \mathrm{mL}$ anti-IFN- $\gamma$ ) at $4^{\circ} \mathrm{C}$. Plates were then washed twice with PBS/Tween 20 solution, and nonspecific binding was blocked using 10\% FCS in PBS for 120 minutes at room temperature. The blocking buffer was removed, and the wells were washed four times. Samples were added and incubated overnight at $4^{\circ} \mathrm{C}$. The wells were washed six times, and a biotinylated $\mathrm{Ab}$ was added (PharMingen) $(20 \mathrm{ng} / \mathrm{mL}$ anti-IL$12 ; 40 \mathrm{ng} / \mathrm{mL}$ anti-IFN- $\gamma$ ) followed by a 30 -minute incubation at room temperature. Next, diluted avidin peroxidase (Boehringer Mannheim, Mannheim, Germany) was added and incubated at room temperature for 30 minutes. The plates were washed eight times, and $100 \mu \mathrm{L}$ of 2,2' -azinobis(3-ethylbenzothiazoline-6-sulfonic acid) (Boehringer Mannheim) was added per well. Plates were read at an optical density of $405 \mathrm{~nm}$. A standard IL-12 and IFN- $\gamma$ curve containing known concentrations of each cytokine was performed.

\section{Cytotoxicity assay}

Cytotoxicity assay was performed according to standard protocols. ${ }^{42}$ Viable splenocytes were isolated from the spleens of animals that underwent the different forms of treatment. Red blood cells were lysed by suspending the splenocytes in $5 \mathrm{~mL}$ of $0.83 \%$ ammonium chloride-potassium lysis buffer. In vitro stimulation was performed for 5 days in 24-well plates, with each well containing $8 \times 10^{6}$ splenocytes and $8 \times 10^{5}$ CT-26 cells treated previously with $150 \mu \mathrm{g} / \mathrm{mL}$ of mitomycin C for 30 minutes at $37^{\circ} \mathrm{C}$. On day 5 , fresh tumor cells were harvested and $1 \times 10^{6} /$ cells were labeled with $150 \mu \mathrm{Ci}$ of ${ }^{51} \mathrm{Cr}$ for 1 hour. After labeling, the cells were washed four times and adjusted to $5 \times 10^{4} / \mathrm{mL}$; next, $100 \mu \mathrm{L}$ of this cell suspension was added to 96-well flat-bottom plates and incubated with effector cells for 5 hours at $37^{\circ} \mathrm{C}$ in different effector to target cell ratios. The spontaneous and maximum release of ${ }^{51} \mathrm{Cr}$ from tumor cells was determined, with the latter using $0.8 \%$ Triton X-100. After incubation, ${ }^{51} \mathrm{Cr}$ radioactivity was measured in $50-\mu \mathrm{L}$ aliquots of the supernatants. Data represent the means of triplicate cultures. The percentage of specific lysis was calculated using the following formula: ([cpm experimental $-\mathrm{cpm}$ background $]) /[\mathrm{cpm}$ maximum - cpm background $]) \times 100$.

\section{Depletion of lymphocytes and tumor growth}

The L3T4 $\mathrm{CD}^{+}{ }^{+}$-specific rat anti-mouse hybridoma GK1-5 and the $\mathrm{CD}^{+}$-specific rat anti-mouse hybridoma H35.17.2 were used to obtain anti-CD4 ${ }^{+}$and anti-CD8 ${ }^{+}$Abs. Ascitic fluid was obtained from pristane-primed nude mice injected with $10^{6}$ hybridoma cells. Abs were prepared by precipitation with ammonium sulfate and dialyzed against PBS. The protein concentration was assessed by optical density at $280 \mathrm{~nm}$. Tumor-bearing mice (three in each group) were depleted of $\mathrm{CD}^{+}{ }^{+}$or $\mathrm{CD}^{+}$cells by an intraperitoneal injection of $300 \mu \mathrm{g}$ of anti-CD4 ${ }^{+}$or anti-CD8 ${ }^{+} \mathrm{Abs}^{43}$ five times on days $-3,-2$,
$-1,7$, and 14. Animals received treatment by an i.t. injection of AdCMVIL-12 on day 0. Tumor growth was assessed two times per week.

\section{Gene transfer efficiency to tumor nodules by in vivo injection of adenovirus}

Tumor-bearing mice were anesthetized with a mixture of ketamine and xylacine. A total of $10^{9} \mathrm{PFU}$ of AdCMVlacZ in $50 \mu \mathrm{L}$ of saline was injected i.t. Animals were sacrificed 2 days later, and the tumors were excised, immediately embedded in optimal cutting temperature compound (Tissue Tek, Zoeterwoude, The Netherlands), and frozen in liquid nitrogen. Sections of $6-\mu \mathrm{m}$ thickness were fixed with glutaraldehyde $(0.5 \%)$ and stained with 5-bromo-4-chloro-3-indoyl- $\beta$-galactosidase as described previously. ${ }^{44}$

\section{RESULTS}

\section{Construction and characterization of AdCMVII-12}

Because IL-12 is heterodimer of p35 and p40 and overexpression of p40 inhibits IL-12 activity, we constructed a bicistronic recombinant adenovirus vector carrying p35 and p40 subunits of the IL-12 gene under the control of the CMV promoter using an IRES sequence from encephalomyocarditis virus, which allows initiation of translation at downstream start codons (Fig 1A). This construction allows coordinated expression of p35 and p40 of the IL-12 gene to obtain maximum bioactivity of IL-12.

Cultured mouse colon cancer CT-26 cells were infected with AdCMVIL-12 and control adenovirus AdCMVlacZ at different MOIs (1000,100, 10, and 1). The supernatant from infected cells was collected for the measurement of IL-12 by specific ELISA for detection of p70 heterodimer of IL-12. No IL-12 production was found in AdCMVlacZ-infected CT-26 cells. In contrast, as shown in Figure $1 \mathrm{~B}$, a dose-dependent production of IL-12 was found in cells infected with AdCMVIL-12. As observed, high levels of IL-12 are obtained at an MOI of 100 , and a still higher production was achieved when the MOI was increased to 1000 .

In vivo gene therapy of established colon cancer by AdCMVIL-12

To determine the antitumor activity of AdCMVIL-12, we s.c. injected CT-26 murine colon cancer cells into syngenic BALB/c mice. When tumor size attained $5 \mathrm{~mm}$ in diameter, tumor-bearing animals were treated by an i.t. injection of AdCMVIL- 12 at $10^{9} \mathrm{PFU}(n=17)$ or $10^{8}$ PFU $(n=17)$, of control adenovirus AdCMVlacZ at $10^{9}$ PFU $(n=16)$, or of saline $(n=14)$. After treatment, the size of the tumors in animals treated with saline or with AdCMVlacZ increased progressively. All animals from these two control groups died, and mortality reached $100 \%$ at day 42 postinoculation (Fig 2, A and B).

In contrast, 13 of 17 animals treated with a high dose of AdCMVIL-12 showed complete regression of the tumor. Also, 13 of 17 animals treated with a low dose of 
A

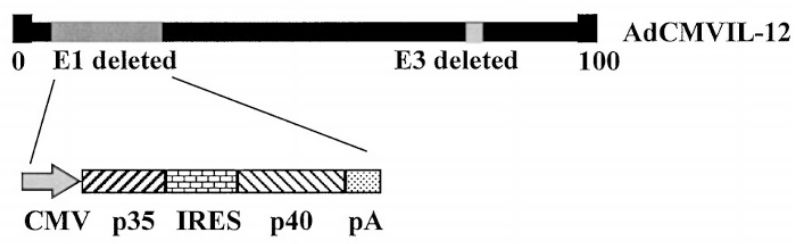

B

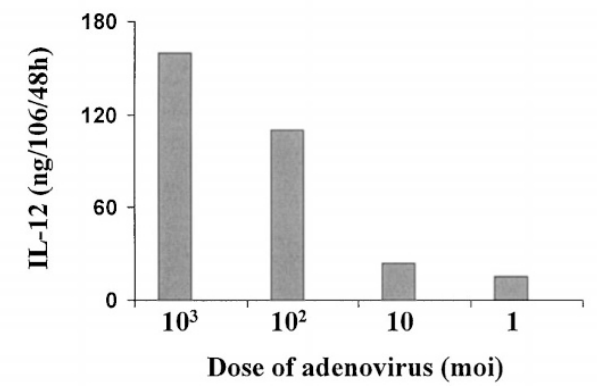

Figure 1. Construction and characterization of AdCMVIL-12. A: Schematic representation of the bicistronic recombinant adenovirus AdCMVIL-12. This vector carries p35 and p40 subunits of the IL-12 gene linked with IRES under the control of the CMV promoter. This expression cassette replaces the $\mathrm{E} 1$ region of the Ad5 genome. B: IL-12 production in CT-26 cells after infection with AdCMVIL-12. CT-26 cells were plated in six-well plates and infected with AdCMVIL-12 or AdCMVlacZ at different MOls. After 48 hours, supernatant was collected for the measurement of IL-12 by ELISA. Data represent the mean of two experiments.

AdCMVIL-12 completely eliminated the neoplasm (Fig 2B). Tumors disappeared between days 7 and 10 after vector administration. Histopathological study of the regressing tumor nodules at 5 days after treatment with AdCMVIL-12 showed extensive areas of necrosis with polymorphs and some mononuclear cell infiltration (Fig 3A). The animals treated with control vector AdCMVlacZ had large nodules composed of undifferentiated carcinoma cells without an associated inflammatory response (Fig 3B). Animals who eliminated the tumor after AdCMVIL-12 treatment remained free of tumor and survived until the time of writing this manuscript (200 days after administration of the vector). Of the remaining eight animals, the tumor was quiescent for a period of 2-5 weeks in six cases; in the other two cases, no apparent effect of the treatment on tumor growth was observed. These results indicate that AdCMVIL-12 even at a low dose $\left(10^{8} \mathrm{PFU}\right)$ has a strong antitumoral effect on established tumors. We also studied gene transfer efficiency in this animal model by i.t. injection of AdCMVlacZ. We found that $\sim 10 \%$ of tumor cells could be effectively transduced after an i.t. injection of $10^{8} \mathrm{PFU}$ of the vector (Fig 3C). It seems that this proportion of transduced cells is enough for the production of IL-12

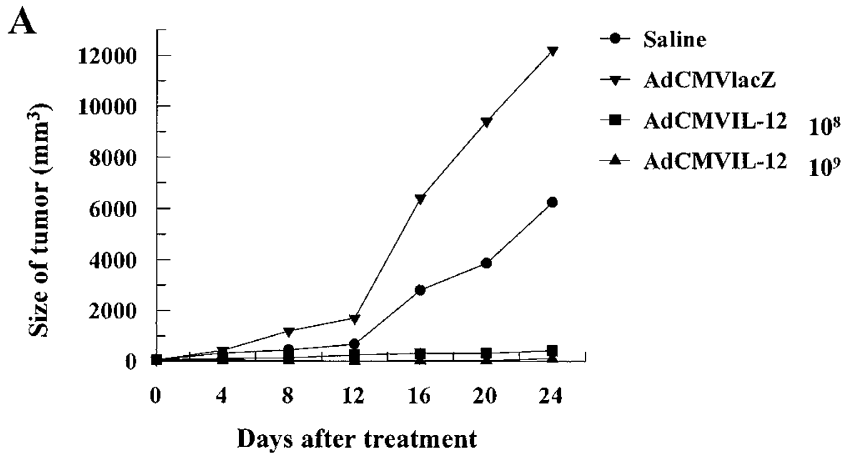

B

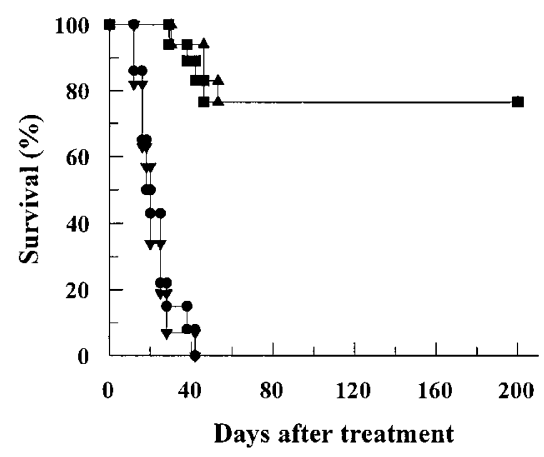

Figure 2. In vivo gene therapy of established colon cancer implanted s.c. Mice with s.c. established colon cancer were treated with either AdCMVIL-12 at $10^{9} \mathrm{PFU}(n=17)$, AdCMVIL-12 at $10^{8}$ PFU $(n=17)$, control adenovirus AdCMVlacZ at $10^{9}$ PFU $(n=16)$, or saline $(n=14)$. The size of the tumor was measured, and deaths of animals were documented. A: Size of tumor after treatment with AdCMVIL-12. B: Long-term survival of animals after treatment with AdCMVIL-12.

in sufficient amounts to induce a strong antitumoral effect.

Local and systemic expression of IL-12 and IFN- $\gamma$ after i.t. injection of AdCMVIL-12

IL-12 is a strong inducer of IFN- $\gamma \cdot{ }^{15,45}$ To analyze the i.t. and systemic levels of IL-12 and IFN- $\gamma$ after the treatment of tumors with AdCMVIL-12, we measured the concentrations of these cytokines in tumor homogenates, sera, and spleens at different time intervals in animals that had been subjected to i.t. injections of AdCMVIL-12 at $10^{8}$ PFU, control adenovirus AdCMVlacZ, or saline. Table 1 shows that a substantial production of both IL-12 and IFN- $\gamma$ takes place in tumors treated with AdCMVIL-12, whereas insignificant or undetectable levels of these cytokines were found in tumors treated with the control adenovirus or saline. Serum or spleen concentrations of IL-12 and IFN- $\gamma$ were under the detection limit of the ELISA in all cases $(<0.03 \mathrm{ng} / \mathrm{mL})$. These results indicate that our vector is able to induce high i.t. levels of both IL-12 and IFN- $\gamma$ without increasing systemic cytokine concentrations. 


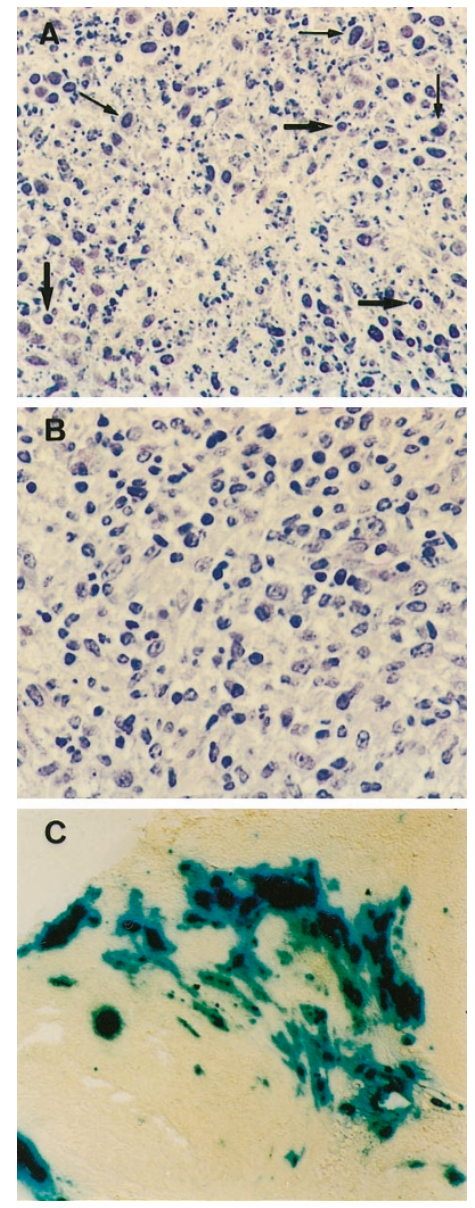

Figure 3. Histological analysis of colon cancer after treatment with different vectors. Animals with established tumors were treated by an i.t. injection of AdCMVIL-12 at $10^{8}$ PFU or with AdCMVlacZ at same dose. After 5 days, tumors were collected for hematoxylin and eosin (H\&E) staining. A: A tumor from an AdCMVIL-12-treated animal. It shows extensive necrotic areas, lymphocyte infiltration (thick arrows), and few remaining tumor cells (thin arrows) (H\&E, $\times 400$ ). B: A tumor from an AdCMVlacZ-treated animal. It shows an undifferentiated carcinoma with no apparent inflammatory component $(H \& E, \times 400)$. C: Gene transfer efficiency in a tumor after i.t. injection of adenoviral vector. At 2 days after i.t. administration of AdCMVlacZ-12 at $10^{8}$ PFU, tumors were collected for 5-bromo-4chloro-3-indoyl- $\beta$-galactosidase staining. The arrow shows adenovirus-transduced cells $(\times 200)$.

Involvement of T-cell subtypes in the regression of colon cancer by AdCMVIL-12

Because IL-12 is very efficient at activating T-cell immunity, we investigated the role of $\mathrm{CD} 4^{+}$and $\mathrm{CD} 8^{+} \mathrm{T}$ cells in mediating the antitumoral effect of AdCMVIL-12. To this aim, in vivo depletion of $\mathrm{CD} 4^{+}$or $\mathrm{CD} 8^{+}$cells was carried out by an intraperitoneal injection of anti-CD4 or anti-CD8 Abs before treatment of the tumors with AdCMVIL-12. The efficiency of $\mathrm{CD}^{+}$and $\mathrm{CD}^{+}$depletion was $>99 \%$ (data not shown) as measured by flow cytometry. As shown in Figure 4, the tumor growth rate in $\mathrm{CD}^{+}$-depleted mice that had been treated with an i.t. injection of AdCMVIL-12 was similar to that observed in untreated controls. In contrast, tumor growth in $\mathrm{CD} 4^{+}$-depleted mice that had received i.t. injections of AdCMVIL-12 was still substantially inhibited compared with untreated animals. In fact, $66 \%$ of $\mathrm{CD}^{+}$-depleted mice treated with AdCMVIL-12 showed complete tumor regression. Thus, our results point to a critical role of $\mathrm{CD} 8^{+} \mathrm{T}$ cells in mediating the anti-oncogenic effect resulting from an i.t. injection of AdCMVIL-12.

\section{AdCMVIL-12 elicits antitumoral cytotoxic T-lymphocyte (CTL) response}

Having shown that $\mathrm{CD} 8^{+} \mathrm{T}$ cells are involved in tumor regression in animals subjected to local treatment with AdCMVIL-12, we further investigated whether this therapy was able to induce a CTL response against colon cancer cells. At 15 days after treatment with $10^{8}$ PFU of AdCMVIL-12, control adenovirus AdCMVlacZ, or saline, spleens from tumor-bearing animals were obtained and were used to analyze specific CTL activity against CT-26 cells. As shown in Table 2, there was no significant CTL activity against CT-26 cells in splenocytes from saline- and AdCMVlacZ-treated animals. In contrast, a high CTL lytic activity against CT-26 cells was detected in splenocytes from animals treated with AdCMVIL-12. A high level of CTL activity was also observed in lymph nodes from AdCMVIL-12-treated animals, but not in lymph nodes from control animals (data not shown). These results indicate that local expression of IL-12 in tumor nodules induces a potent systemic CTL activity against colon cancer cells.

\section{Local AdCMVIL-12 gene therapy of colon cancer induces distant antitumoral effects}

Because a systemic antitumoral CTL response was elicited by local administration of AdCMVIL-12, we evaluated whether injection of AdCMVIL-12 into a tumor nodule had any effect on distant tumoral lesions. To this aim, we used an animal model with implanted bilateral tumor nodules in which only one of the tumors was treated. Thus, mice were injected s.c. with CT-26 cells bilaterally and, when tumor nodules were $5 \mathrm{~mm}$ in diameter on both sides, tumors on the right side were treated with an i.t. injection of $10^{8}$ PFU of AdCMVIL-12 $(n=7)$ or AdCMVlacZ $(n=4)$. All animals that were treated with control AdCMVlacZ showed progressive tumor growth on both sides and finally died. However, treatment with AdCMVIL-12 induced complete regression of the tumor on the right side (treated tumor) in five of seven animals (Fig 5A); more importantly, this treatment also induced complete regression of the tumor on the left side (untreated tumor) in three of seven animals and partial left tumor regression in the rest of the animals (Fig 5B). These data suggest that a local i.t. injection of AdCMVIL-12 can eradicate treated tumors and activate a specific CTL response that is able to control tumor growth at distant sites. 
Table 1. IL-12 and IFN- $\gamma$ Cytokine Production After I.t. Injection of AdCMVIL-12

\begin{tabular}{|c|c|c|c|c|}
\hline \multirow[b]{2}{*}{ Cytokines } & \multirow[b]{2}{*}{ Groups } & \multicolumn{3}{|c|}{ Days posttreatment } \\
\hline & & 1 & 3 & 5 \\
\hline \multirow[t]{3}{*}{ IL-12 } & AdCMVIL-12 & $1.1(0.036)^{\star}$ & $5.7(0.14)$ & ND† \\
\hline & AdlacZ & $0.03(0.011)$ & $0.04(0.02)$ & ND \\
\hline & Saline & $0.15(0.04)$ & $0.24(0.032)$ & ND \\
\hline \multirow[t]{3}{*}{ IFN- $\gamma$} & AdCMVIL-12 & ND & $0.05(0.05)$ & $0.01(0.16)$ \\
\hline & AdCMVlacZ & ND & $<0.03 \ddagger$ & $<0.03$ \\
\hline & Saline & ND & $<0.03$ & $<0.03$ \\
\hline
\end{tabular}

${ }^{*}$ Numbers represent the mean of three animals per group (nanograms per milligram of tumor tissue) for each cytokine. SD is expressed in parenthesis.

†ND, not determined.

¥Under the level of detection.

Long-term antitumor immunity induced by i.t. injection of AdCMVIL-12

To determine whether local treatment of tumor nodules with AdCMVIL-12 can induce lasting immunological memory, we rechallenged animals that were free of tumors after AdCMVIL-12 treatment with a new s.c. administration of CT-26 cells at 2 weeks, 2 months, and 4 months after complete regression of primary tumors. Figure 6A shows that when animals were rechallenged at day 14 after tumor disappearance, all animals (10 of 10) rejected the s.c. implantation of $5 \times 10^{5}$ parental CT-26 cells. When animals were rechallenged with parental CT-26 cells at 2 and 4 months after the disappearance of the initial tumor, 1 of 11 animals and 0 of 6 animals developed tumors, respectively (Fig 6, B and C). The protection was observed in $96.4 \%$ of all animals that eliminated the initial neoplasm after AdCMVIL-12 therapy. By contrast, in the control group, 22 of 22 mice developed a s.c. tumor after inoculation of CT-26 cells. These data indicate that in vivo gene therapy using

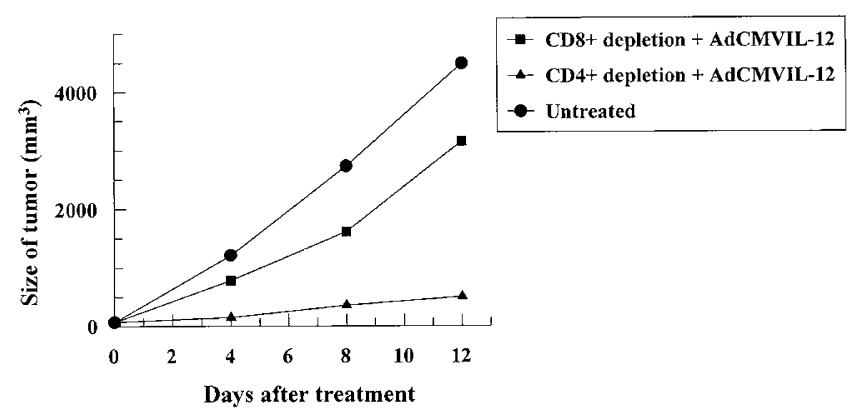

Figure 4. Involvement of T-cell subtypes in the anti-oncogenic effect of AdCMVIL-12. Depletion of $\mathrm{CD}^{+}{ }^{+}$or $\mathrm{CD}^{+} \mathrm{T}$ cells was carried out by injection of anti-CD4 ${ }^{+}$or anti-CD8 ${ }^{+} \mathrm{Ab}$ into tumor-bearing animals before and after local treatment of tumors with AdCMVIL12. Depletion of $\mathrm{CD}^{+} \mathrm{T}$ cells abrogates the antitumoral effect of the treatment (tumor growth rate is similar to that of untreated controls). Depletion of $\mathrm{CD}^{+}{ }^{+} \mathrm{T}$ cells does not substantially affect the antitumoral effect of the treatment; in these animals, the tumor growth rate is still markedly inhibited compared with untreated controls.
Table 2. CTL Activity in Splenocytes After an I.t. Injection of AdCMVIL-12

\begin{tabular}{lcc}
\hline & \multicolumn{2}{c}{ Cytotoxic index (\%) } \\
\cline { 2 - 3 } \multicolumn{1}{c}{ Groups } & $33: 1^{*}$ & $11: 1$ \\
\hline AdCMVIL-12 & $42.3 \dagger$ & 22.1 \\
AdCMVlacZ & -0.11 & -0.4 \\
Saline & -0.7 & -0.05 \\
Control & 0.73 & 0.12 \\
\hline
\end{tabular}

*Effector to target cell ratios.

†Mean values for three animals per group.

AdCMVIL-12 vector can induce long-term protection against tumor recurrence.

\section{DISCUSSION}

As in other tumors, the progression of colon cancer with local growth, invasion of regional lymph nodes, and distant metastasis in the presence of an intact immune system indicates that malignant cells have developed highly efficient mechanisms to evade immunosurveillance. In fact, many investigators have observed improved survival in cases with an apparent immunological response in regional lymph nodes and an even greater increase in survival when this feature was present with a local inflammatory reaction to the primary tumor. ${ }^{46,47}$

IL-12 is a key factor in the orchestration of cell immunity, promoting $\mathrm{T}$ helper type 1 responses. ${ }^{10}$ This cytokine has been shown to be very effective in stimulating host antitumoral responses in different animal models of solid tumors and also in human clinical

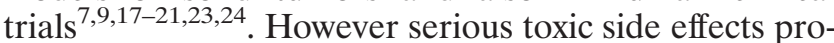
hibit the use of IL-12 by the systemic route. ${ }^{23,24}$ Thus, procedures allowing local production of the cytokine within the tumor mass to activate the immunological reaction against the neoplasm could lead to tumor regression without accompanying toxicities.

Local production of IL-12 can be achieved by gene transfer methodologies. Gene gun, vaccinia virus, adenovirus, and direct injection of plasmid have been used to transfer IL-12 genes to the tumor that demonstrate antitumoral effects in various solid neoplasms in different animal models. ${ }^{29-36}$ With respect metastatic colon cancer, prolonged survival was reported when adenovirus encoding IL-12 was administered i.t. to the poorly immunogenic cell line MCA-26, although mechanisms of the antitumoral effect were not investigated. ${ }^{33}$

In the present work, we have used an adenovirus expressing high levels of bioactive IL-12 in a murine model of colon cancer using the CT-26 cell line. This cell line is poorly immunogenic and does not induce significant cytotoxic T-cell responses by itself. ${ }^{48,49}$ An adenoviral vector was selected because it does not integrate into the cell genome and because it can transduce dividing and nondividing cells in vivo with great efficiency; in addition, although it allows a strong local expression of IL-12, the expression is transient and there 
A

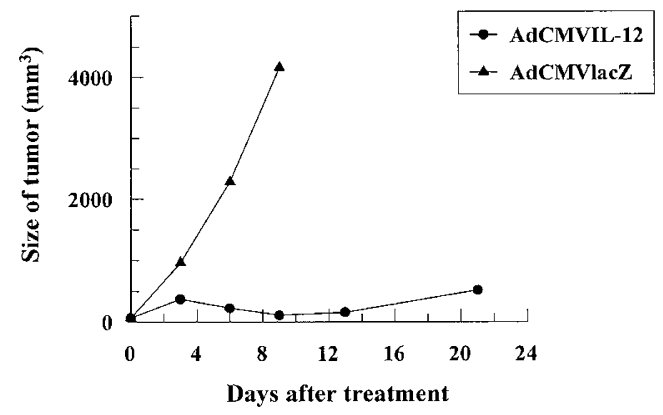

B

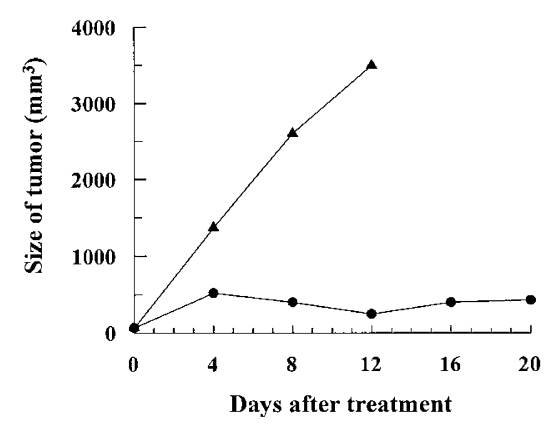

Figure 5. Local AdCMVIL-12 gene therapy of one tumor (right side) induces a distant antitumoral effect on the contralateral tumor (left side) in animals with bilateral established tumors. A: Size of the tumor on the right side (treated tumor) in animals that received an i.t. injection of AdCMVIL-12 (10 8 PFU) or control adenovirus AdCMVlacZ (10 ${ }^{8}$ PFU). B: Size of the tumor on the left side (untreated tumor) in animals in which the right side tumor was treated with AdCMVIL-12 $\left(1 \times 10^{8} \mathrm{PFU}\right)$ or control adenovirus AdCMVlacZ $\left(1 \times 10^{8} \mathrm{PFU}\right)$.

is not risk of sustained stimulation of the immune system as can occur with retroviruses and other integrating vectors. AdCMVIL-12 was constructed to permit the coordinated production of $\mathrm{p} 40$ and $\mathrm{p} 35$ to obtain the maximum IL-12 bioactivity, because an excess of p40 could lead to the formation of p40 homodimers, which can combine with IL-12 receptor to reduce the antitumoral effect of the cytokine. ${ }^{35}$

In the present study, we show that injection of AdCMVIL-12 directly into the neoplastic nodule is followed by local production of high levels of IL-12 and IFN- $\gamma$, with IL-12 values near $6 \mathrm{ng} / \mathrm{mg}$ of tumor at day 3 postinoculation and IFN- $\gamma$ values near $0.1 \mathrm{ng} / \mathrm{mg}$ of tumor at day 5. The induction of IFN- $\gamma$ after tumor transduction with AdCMVIL-12 indicates that the IL-12 produced by tumor cells is biologically active and exerts its characteristic immunoregulatory functions. Importantly, systemic levels of these cytokines were undetectable, a finding that correlates with the absence of toxic effects in animals receiving the treatment.

Between days 7 and 10 after AdCMVIL-12 inoculation, the tumor regressed in $94 \%$ of animals; complete
A

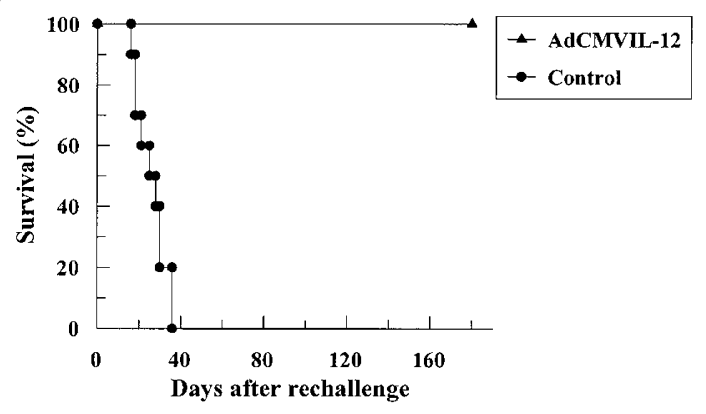

B

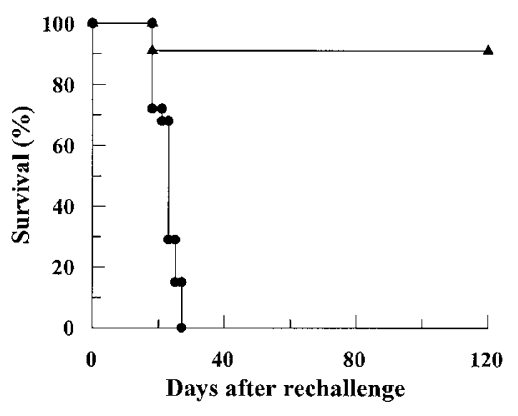

C

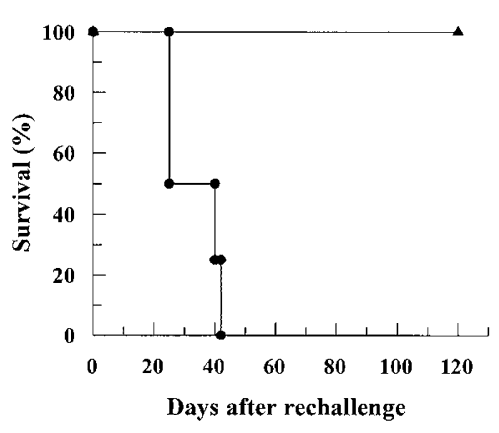

Figure 6. Long-term protection against parental colon cancer cell rechallenge at distant sites. CT-26 cells $\left(5 \times 10^{5}\right.$ cells $)$ were inoculated s.c. in the flanks of animals that had been cured after treatment of established tumor with AdCMVIL-12 and also in the flanks of age- and sex-matched naive animals. Deaths of animals were documented, and results were expressed as the percentage of animal survival. A: Animals inoculated with CT-26 cells 14 days after complete regression of the initial tumor $(n=10)$. B: Animals inoculated with CT-26 cells 2 months after complete regression of the initial tumor $(n=11)$. C: Animals inoculated with CT-26 cells 4 months after complete regression of the initial tumor $(n=6)$.

disappearance of the lesion was seen in $76 \%$ of treated mice. Results were comparable with a low $\left(10^{8} \mathrm{PFU}\right)$ or high $\left(10^{9} \mathrm{PFU}\right)$ dose of the vector, indicating a wide therapeutic window for this form of therapy. Regression of the tumor was associated with prolonged survival; those animals that responded with complete tumor regression remained alive up to the moment of writing this manuscript (200 days after vector administration). In our system, tumor rejection appears to be mediated mainly by $\mathrm{CD} 8^{+}$cells, because depletion of this lympho- 
cyte subpopulation, but not of $\mathrm{CD}^{+}$cells, largely abrogated the inhibition of tumor growth caused by AdCMVIL-12 treatment. This finding, together with the emergence of a potent CTL response against tumor cells in animals treated with AdCMVIL-12, indicates that immune rejection is the basic mechanism of the antitumoral effect of the therapy. Other mechanisms, including anti-angiogenic effects of IL-12, IFN- $\gamma$, or IFN- $\gamma$ induced factors, ${ }^{50-52}$ could also contribute to the antioncogenic potential of the procedure.

Recently, Toda et $\mathrm{al}^{36}$ have shown that i.t. inoculation of a combination of replication-competent herpes simplex virus (HSV) plus defective HSV vector encoding IL-12 in a murine model of colon cancer induced cytotoxic T-cell responses and increased survival. However, the mortality of treated animals reached $100 \%$ at week 7 after therapy. In this study, i.t. IL-12 levels were low and $\sim 50-100 \mathrm{pg} /$ tumor was produced in vectorinoculated tumors at 5 days postinoculation. ${ }^{36}$ It seems possible that the limited antitumoral effect could be due to low in vivo transduction efficiency using HSV vectors.

In our study, as in the report by Toda et $\mathrm{al}^{36}{ }^{36}$ the generation of CTL responses against tumor cells could explain the important inhibition of tumor growth observed in lesions distant to the nodule treated with AdCMVIL-12. The protection obtained by activation of antitumoral immunity was also evident in experiments showing that animals that eliminated the tumor after i.t. administration of AdCMVIL-12 resisted a new challenge with tumor cells administered up to 4 months after the disappearance of the initial tumor.

These important properties of in vivo tumor transduction with IL-12 are relevant when considering potential applications in humans. As mentioned, the presence of an immune reaction against primary colon cancer or lymph node metastasis in the surgical specimen has been recognized as a factor improving prognosis. ${ }^{46,47}$ However, circulating tumoral cells have been found in the portal vein at the time of surgery, a finding which may be related to the occurrence of metachronous metastasis. ${ }^{53}$ Thus, it seems possible that transduction of the primary tumor with vectors expressing IL-12 at endoscopy, before the intervention, may favor the prognosis and reduce recurrences after surgery by stimulating specific CTL responses that could eliminate small metastatic foci. In addition, this therapy could also be of value in advanced metastatic disease, a situation for which there is no effective treatment available at present.

\section{ACKNOWLEDGMENTS}

We thank Pilar Alzuguren and Roberto Bilbao for their expert assistance. This work was supported in part by SAF 98-0146 from Comision Interministerial de Ciencia y Tecnologia (CICYT) a Fundación Mapfre Medicina and Inés Bemberg Grant, and also by J. Vidal, Dr. Cervera, and M. Mendez grants for gene therapy.

\section{REFERENCES}

1. Cohen AM, Minsky BD, Schilsky RL. Cancer of the colon. In: DeVita T Jr., Hellman S, Rosemberg SA, eds. Cancer. Principles, and Practice of Oncology. 5th ed. Philadelphia: Lippincott-Raven; 1997:1144-1197.

2. Willet CG, Tepper JE, Cohen AM, Orlow E, Welch C. Failure patterns following curative resection of colonic carcinoma. Ann Surg. 1984;200:685-690.

3. Cohen AM, Tremittera S, Candela F, Thaler JT, Sigurdson ER. Prognosis of node-positive colon cancer. Cancer. 1991;67:1859-1861.

4. Ries LA, Miller BA, Hankey BF, Kosary C, Harras A, Edwards B, eds. SEER Cancer Statistics Review, 1973-1991. Bethesda, Md: National Cancer Institute; 1994. National Institutes of Health Publication No. 92-2789.

5. Zier K, Gansbacher B, Salvadori S. Preventing abnormalities in signal transduction of T cells in cancer: the promise of cytokine gene therapy. Immunol Today. 1996;17:39-45.

6. Musiani P, Modesti A, Giovarella M, et al. Cytokine, tumor-cell death, and immunogenicity: a question of choice. Immunol Today. 1997;18:32-36.

7. Schmidt-Wolf G, Schmidt-Wolf GH. Cytokines and gene therapy. Immunol Today. 1995;16:173-175.

8. Colombo M, Forni G. Cytokine gene transfer in tumor inhibition and tumor therapy: where are we now? Immunol Today. 1994;15:48-51.

9. Stern LL, Tarby CM, Tamborini B, Truitt GA. Preclinical development of IL-12 as an anticancer drug: comparison to IL-2. Proc Annu Meet Am Assoc Cancer Res. 1994;35: A3100.

10. Lamonta A, Adorini L. IL-12: a key cytokine in immune regulation. Immunol Today. 1996;17:214-217.

11. Wolf SF, Temple PA, Kobayashi M, et al. Cloning of cDNA for natural killer cell stimulatory factor, a heterodimeric cytokine with multiple biologic effects on $\mathrm{T}$ and natural killer cells. J Immunol. 1991;146:3074-3081.

12. Seder RA, Gazzinelli R, Sher A, Paul WE. IL-12 acts directly on $\mathrm{CD}^{+} \mathrm{T}$ cells to enhance priming for IFN- $\gamma$ production and diminishes IL-4 inhibition of such priming. Proc Natl Acad Sci USA. 1993;90:10188-10192.

13. Gately MK, Warrier RR, Honasoge S, et al. Administration of recombinant IL-12 to normal mice enhances cytolytic lymphocyte activity and induces production of IFN- $\gamma$ in vivo. Int Immunol. 1994;6:157-167.

14. Manetti R, Gerosa F, Giudizi MG, et al. Interleukin-12 induces stable priming for interferon $\gamma($ IFN- $\gamma$ ) production during differentiation of human $\mathrm{T}$ helper (Th) cells and transient IFN- $\gamma$ production in established Th2 cell clones. J Exp Med. 1994;179:1273-1283.

15. Trinchieri G. Interleukin-12 and its role in the generation of Th1 cells. Immunol Today. 1993;14:335-338.

16. Hendrzak JA, Brunda MJ. Interleukin 12: biological activity, therapeutic utility, and role in disease. Lab Invest. 1995;72:619-637.

17. Brunda MJ, Luistro LL, Warrier RR, et al. Antitumor and antimetastatic activity of interleukin 12 against murine tumors. J Exp Med. 1993;178:1223-1230.

18. $\mathrm{Mu} \mathrm{J}$, Zou JP, Yamamoto N, et al. Administration of recombinant interleukin-12 prevents outgrowth of tumor cells metastasizing spontaneously to lung and lymph nodes. Cancer Res. 1995;5:4404-4408.

19. Tannenbaum CS, Wicker N, Armstrong D, et al. Cytokine and chemokine expression in tumors of mice receiving systemic IL-12 therapy. J Immunol. 1996;156:693-699. 
20. Noguchi Y, Jungbluth A, Richards E, Old L. Effect of interleukin 12 on tumor induction by 3-methylcolantrene. Proc Natl Acad Sci USA. 1996;93:11798-11801.

21. Brunda MJ, Luistro J, Hendrzak JA, Fountoluakis M, Garotta G, Gately MK. Role of interferon- $\gamma$ in mediating the antitumor efficacy of interleukin-12. J Immunother. 1995;17:71-77.

22. Orange JS, Salazar-Mather TP, Opal SM, et al. Mechanisms of interleukin 12-mediated toxicities during experimental viral infections: role of tumor necrosis factor and glucocorticoids. J Exp Med. 1995;181:901-914.

23. Marshall E. Cancer trial of interleukin-12 halted. Science. 1995;268:1555.

24. Jenks S. After initial setback, IL-12 regaining popularity. J Natl Cancer Inst. 1996;88:576-577.

25. Cavallo F, Signorelli P, Giovarelli M, et al. Antitumor efficacy of adenocarcinoma cell engineered to produce interleukin-12 (IL-12) or other cytokines compared with exogenous IL-12. J Natl Cancer Inst. 1997;89:1049-1058.

26. Bannei R, Arroyo CD, Cordon-Cardo C, et al. The role of IL-12 secreted from genetically modified tumor cells in the establishment of antitumor immunity. J Immunol. 1994; 152:2324-2332.

27. Tahara H, Zeh HJ III, Storkus WJ, et al. Fibroblasts genetically engineered to secrete interleukin-12 can suppress tumor growth and induce antitumor immunity to a murine melanoma in vivo. Cancer Res. 1994;54:182-189.

28. Martinotti A, Stoppacciaro A, Vagliani M, et al. CD4 T cells inhibit in vivo the CD8-mediated immune response against murine colon carcinoma cells transduced with interleukin-12 genes. Eur J Immunol. 1995;25:137-146.

29. Rakhmilevich AL, Turner J, Ford J, et al. Gene gunmediated skin transfection with interleukin 12 gene results in regression of established primary and metastatic murine tumors. Proc Natl Acad Sci USA. 1996;93:6921-6296.

30. Rakhmilevich AL, Janssen K, Turner J, Culp J, Yang N. Cytokine gene therapy using gene gun technology: superior antitumor activity of interleukin-12. Hum Gene Ther. 1997;8:1303-1311.

31. Meko JB, Yim JH, Tsung K, Norton JA. High cytokine production and effective antitumor activity of a recombinant vaccinia virus encoding murine interleukin 12. Cancer Res. 1995;55:4765-4770.

32. Tan J, Newton CA, Djeu JY, et al. Injection of complementary DNA encoding interleukin-12 inhibits tumor establishment at distant sites in a murine renal carcinoma model. Cancer Res. 1996;56:3399-3403.

33. Caruso M, Pham-Nguyen K, Kwong Y, et al. Adenovirusmediated interleukin-12 gene therapy for metastatic colon carcinoma. Proc Natl Acad Sci USA. 1996;93:11302-11306.

34. Bramson JL, Hitt M, Addison CL, Muller WJ, Gauldie J, Graham FL. Direct intratumoral injection of an adenovirus expressing interleukin-12 induces regression and longlasting immunity that is associated with highly localized expression of interleukin-12. Hum Gene Ther. 1996;7: 1995-2202.

35. Chen L, Chen D, Block E, O'Donnell M, Kufe DW, Clinton SK. Eradication of murine bladder carcinoma by intratumor injection of a bicistronic adenoviral vector carrying cDNAs for the IL-12 heterodimer and its inhibition by the IL-12 p40 subunit homodimer. I Immunol. 1997; 159:351-359.

36. Toda M, Martuza RL, Kojima H, Rabkin S. In situ cancer vaccination: an IL-12 defective vector/replication-competent HSV combination induces local and systemic antitumor activity. J Immunol. 1998;160:4457-4464.
37. Blaese M, Blankestein T, Brenner M, et al. Vectors in cancer therapy: how will they deliver? Cancer Gene Ther. 1995;2:291-297.

38. Qian C, Bilbao R, Bruña O, Prieto J. Induction of sensitivity to ganciclovir in human hepatocellular carcinoma cells by adenovirus-mediated gene transfer of herpes simplex virus thymidine kinase. Hepatology. 1995; 22:118-123.

39. Brattain MG, Strobel-Stevenson J, Find D, Webb M, Sarrif AM. Establishment of mouse colonic carcinoma cell lines with different metastatic properties. Cancer Res. 1980;40:2142-2146.

40. Corbett TH, Griswald DD, Roberts BJ, Peckham JC, Schabel FM. Tumor induction relationships in development of transplantable cancers of the colon in mice for chemotherapy assay with a note on carcinogen structure. Cancer Res. 1975;35:2434-2439.

41. Chensue SW, Ruth JH, Warmington K, Lincoln O, Kunkel SL. In vivo regulation of macrophage IL-12 production during type 1 and type 2 cytokine-mediated granuloma formation. J Immunol. 1995;155:3546-3551.

42. Coligan JE, Kruisbeck AM, Marguiles DH, Sevach EM, Strober W. Currents Protocols in Immunology. New York: Wiley-Interscience; 1994:3.11.1-3.11.20.

43. Lasarte JJ, Sarobe P, Prieto J, Borrás-Cuesta F. In vivo cytotoxic T-lymphocyte induction may take place via $\mathrm{CD}^{+}$helper lymphocytes. Res Immunol. 1995;146:35-44.

44. Qian C, Idoate M, Bilbao R, et al. Gene transfer and therapy with adenoviral vector in rats with diethylnitrosamine-induced hepatocellular carcinoma. Hum Gene Ther. 1997;8:349-358.

45. Nastala CL, Edington HD, McKinney TG, et al. Recombinant IL-12 administration induces tumor regression in association with IFN- $\gamma$ production. J Immunol. 1994;153: 1697-1706.

46. Murray D, Hreno A, Dutton J, et al. Prognosis in colon cancer: a pathologic reassessment. Arch Surg. 1975;110: 908-913.

47. Pihl E, Malahy MA, Khankhanian N, Hersh EM, Mavligit GM. Immunomorphological features of prognosis significance in Duke's class B colorectal carcinoma. Cancer Res. 1977;37:4145-4149.

48. Fearon ER, Itaya T, Hunt B, Vogelstein B, Frost P. Induction in a murine tumor of immunogenic tumor variants by transfection with a foreign gene. Cancer Res. 1988;35:2975-2980.

49. Huang AYC, Gulden PH, Woods MC, et al. The immunodominant major histocompatibility complex class I-restricted antigen of a murine colon tumor derives from an endogenous retroviral gene product. Proc Natl Acad Sci USA. 1996;93:9730-9725.

50. Voest EE, Kenyan BM, O'Reilly MS, Truitt G, Damato RJ, Folkman Y. Inhibition of angiogenesis in vivo by interleukin-12. J Natl Cancer Inst. 1995;8:581-586.

51. Watanabe Y, Kuribayashi K, Miyatake S, et al. Exogenous expression of mouse interferon $\gamma$ cDNA in mouse neuroblastoma $\mathrm{C} 1300$ cells results in reduced tumorigenicity by augmented antitumor immunity. Proc Natl Acad Sci USA. 1989;86:9456-9460.

52. Farrar MA, Schreiber RD. The molecular cell biology of interferon- $\gamma$ and its receptor. Annu Rev Immunol. 1993;11: $571-611$.

53. Copeland EM, Miller LD, Jones RS, et al. Prognostic factors in carcinoma of the colon and rectum. Am J Surg. 1968;116:875-881. 